\title{
Statin use in patients with chronic kidney disease stages 2-4: targeting beyond improved mortality rates
}

\author{
Kosmas I. Paraskevas · Alexandros A. Tzovaras • \\ Vassilios Stathopoulos • Dimitri P. Mikhailidis
}

Received: 5 November 2009/Accepted: 5 November 2009/Published online: 1 January 2010

(C) Springer Science+Business Media, B.V. 2009

The well-designed study by Neves et al. [1] showed that statin and/or vitamin D non-use were independent risk factors of mortality $(p=0.005)$ in their cohort of patients $(n=95)$ with chronic kidney disease (CKD) stages 4 and 5 (mean estimated glomerular filtration rate $[\mathrm{eGFR}]=16.1 \mathrm{ml} / \mathrm{min} / 1.73 \mathrm{~m}^{2}$ ). After a mean follow-up of $24.1 \pm 9.8$ months, all patients receiving both statins and vitamin $\mathrm{D}$ were alive (18 of 18 patients; $100 \%)$. In contrast, only 24 of the 43 patients (56.4\%) receiving neither a statin nor vitamin $\mathrm{D}$ were alive at the end of the study [1].

Statin use in patients with CKD offers several advantages besides improving mortality rates. Cardiovascular disease (CVD) is the leading cause of death in patients with stages 4 and 5 CKD $[2,3]$.

K. I. Paraskevas $(\bowtie)$

Department of Vascular Surgery, Red Cross Hospital, Athens, Greece

e-mail: paraskevask@hotmail.com

A. A. Tzovaras

1st Department of Oncology, Aghios Savvas Hospital,

Athens, Greece

V. Stathopoulos

2nd Department of Surgery, General Hospital of Rhodos, Rhodos, Greece

D. P. Mikhailidis

Department of Clinical Biochemistry (Vascular Disease

Prevention Clinics), Royal Free Hospital Campus, University College London Medical School, University

College London (UCL), London, UK
Mortality from CVD in this population is approximately 10 to 20 times higher than in the general population [4]. In an analysis of the Pravastatin Pooling Project [5], a subject-level database combining the results from 3 randomized trials of the effects of pravastatin $40 \mathrm{mg} /$ day vs. placebo, the benefit induced by statin use on CVD risk in 19,700 participants with mild/moderate CKD was determined. The 3 randomized studies included in this analysis were the following: the Cholesterol and Recurrent Events (CARE) trial [6], the Long-term Intervention with Pravastatin in Ischemic Disease (LIPID) study [7] and the West of Scotland Coronary Prevention Study (WOSCOPS) [8]. Of the 19,700 total participants in these studies, 12,333 (62.6\%) had mild CKD, as defined by an estimated glomerular filtration rate (eGFR) of 60 to $89.9 \mathrm{ml} / \mathrm{min} / 1.73 \mathrm{~m}^{2}$ and 4,491 (22.8\%) had moderate CKD as defined by an eGFR of 30 to $59.9 \mathrm{ml} / \mathrm{min} / 1.73 \mathrm{~m}^{2}$. Pravastatin significantly reduced the adjusted incidence of the primary outcome of coronary mortality, non-fatal myocardial infarction and coronary revascularization (hazard ratio [HR], 0.77; 95\% confidence interval [CI] 0.68-0.86) and the expanded outcome (cardiovascular mortality, non-fatal myocardial infarction, coronary revascularization or stroke; HR, 0.79; $95 \%$ CI 0.71-0.88) in people with moderate CKD [5]. Thus, the effects of statin use in patients with CKD not only include reduction of mortality rates, but also a decrease in CVD events (non-fatal myocardial infarction, stroke and revascularization episodes). 
Neves et al. [1] correctly mention that in the German Diabetes and Dialysis (Die Deutsche Diabetes Dialyse Studie; 4D) study [9], death from all causes was similar in the atorvastatin and the placebo groups (297 vs. 320 patients, or 48 vs. $50 \%$, respectively; RR 0.93 , 95\% CI $0.79-1.08 ; p=0.33$ ). However, atorvastatin therapy resulted in a significant reduction of all cardiac events combined compared with placebo (205 vs. 246 events, or 33 vs. $39 \%$, respectively; RR 0.82, 95\% CI 0.68-0.99; $p=0.03$ ). There was also a trend toward a smaller percentage of deaths from cardiac causes (121 vs. 149 deaths, or 20 vs. $23 \%$, respectively; RR $0.81,95 \%$ CI $0.64-1.03$; $p=0.08$ ) [9]. These results should not be viewed as non-significant.

Patients with nephrotic syndrome in CKD stages 1 through 4 have both an increased production and a decreased catabolism of low-density lipoprotein (LDL) cholesterol, resulting in increased total and LDL-cholesterol levels [10]. Hypertriglyceridemia may also occur, probably due to a reduction in apolipoprotein C-II activity and the presence of a lipoprotein lipase inhibitor, causing decreased activity of lipoprotein lipase and thus decreased catabolism of triglycerides [10]. In contrast, patients with non-nephrotic CKD stages 2 through 4 tend to have normal LDL-cholesterol levels, decreased HDLcholesterol levels and elevated triglycerides; these alterations are probably due to the above-mentioned reduced lipoprotein lipase activity [10]. As a result, an increase in the LDL/HDL ratio occurs, which, together with elevated lipoprotein (a) levels, contribute to the atherosclerotic complications of these patients [11]. Thus, patients with CKD also have moderate/advanced atherosclerosis in other arterial beds, such as the carotids [12, 13] and/or the heart [14].

Among other studies, the GREek Atorvastatin and Coronary heart disease Evaluation (GREACE) trial showed that renal and ischemic heart disease may progress in parallel and therefore, statins may be beneficial to both organs [15-17]. Several studies have demonstrated that statins improve renal function [18-20]; thus, their use in patients with CKD is virtually mandatory so as to reduce CKD progression and renal function decline rates.

Statin use in patients with CKD is coupled with several beneficial actions. Although mortality rates are an important issue, they should not be the only criterion determining whether patients with CKD merit being on routine statin use or not. All patients with CKD should receive statins to reduce the decline of their kidney function and improve their CVD risk.

\section{References}

1. Neves PL, Malho A, Cabrita A et al (2009) Statins and vitamin D: a friendly association in pre-dialysis patients. Int Urol Nephrol. doi:10.1007/s11255-009-9634-x

2. Molitch ME (2006) Management of dyslipidemias in patients with diabetes and chronic kidney disease. Clin J Am Soc Nephrol 1:1090-1099

3. Banerjee D, Contreras G, Jaraba I et al (2009) Chronic kidney disease stages 3-5 and cardiovascular disease in the veterans affairs population. Int Urol Nephrol 41:443-451

4. Meyer KB, Levey AS (1998) Controlling the epidemic of cardiovascular disease in chronic renal disease: report from the National Kidney Foundation Task Force on cardiovascular disease. J Am Soc Nephrol 9(12 Suppl):S31-S42

5. Tonelli M, Isles C, Curhan GC et al (2004) Effect of pravastatin on cardiovascular events in people with chronic kidney disease. Circulation 110:1557-1563

6. Sacks FM, Pfeffer MA, Moye LA et al (1996) The effect of pravastatin on coronary events after myocardial infarction in patients with average cholesterol levels. Cholesterol and recurrent events trial investigators. $\mathrm{N}$ Engl J Med 335:1001-1009

7. The Long-Term Intervention with Pravastatin in Ischaemic Disease (LIPID) Study Group (1998) Prevention of cardiovascular events and death with pravastatin in patients with coronary heart disease and a broad range of initial cholesterol levels. N Engl J Med 339:1349-1357

8. Shepherd J, Cobbe SM, Ford I et al (1995) Prevention of coronary heart disease with pravastatin in men with hypercholesterolemia. West of Scotland Coronary Prevention Study Group. N Engl J Med 333:1301-1307

9. Wanner C, Krane V, März W et al (2005) Atorvastatin in patients with type 2 diabetes mellitus undergoing hemodialysis. N Engl J Med 353:238-248

10. Farbakhsh K, Kasiske BL (2005) Dyslipidemias in patients who have chronic kidney disease. Med Clin North Am 89:689-699

11. Paraskevas KI (2008) Statin therapy in peritoneal dialysis patients: effects beyond lipid lowering. Int Urol Nephrol 40:165-170

12. Gelev S, Spasovski G, Dzikova S et al (2008) Vascular calcification and atherosclerosis in hemodialysis patients: what can we learn from the routine clinical practice? Int Urol Nephrol 40:763-770

13. Turgut F, Kanbay M, Metin MR et al (2008) Magnesium supplementation helps to improve carotid intima media thickness in patients on hemodialysis. Int Urol Nephrol 40:1075-1082

14. Civilibal M, Oflaz H, Caliskan S et al (2009) Left ventricular systolic and diastolic function and carotid 
intima-media thickness in pediatric dialysis patients. Int Urol Nephrol 41:401-408

15. Athyros VG, Papageorgiou AA, Elisaf M, Mikhailidis DP, GREACE Study Collaborative Group (2003) Statins and renal function in patients with diabetes mellitus. Curr Med Res Opin 19:615-617

16. Athyros VG, Mikhailidis DP, Papageorgiou AA et al (2004) The effect of statins versus untreated dyslipidaemia on renal function in patients with coronary heart disease. A subgroup analysis of the Greek atorvastatin and coronary heart disease evaluation (GREACE) study. J Clin Pathol 57:328-334

17. Athyros VG, Elisaf M, Papageorgiou AA, GREACE Study Collaborative Group et al (2004) Effect of statins versus untreated dyslipidemia on serum uric acid levels in patients with coronary heart disease: a subgroup analysis of the GREek Atorvastatin and Coronary-heart-disease Evaluation (GREACE) study. Am J Kidney Dis 43:589-599

18. Rysz J, Aronow WS, Stolarek RS et al (2009) Nephroprotective and clinical potential of statins in dialyzed patients. Expert Opin Ther Targets 13:541-550

19. Youssef F, Gupta P, Seifalian AM et al (2004) The effect of short-term treatment with simvastatin on renal function in patients with peripheral arterial disease. Angiology 55:53-62

20. Alnaeb ME, Youssef F, Mikhailidis DP et al (2006) Shortterm lipid-lowering treatment with atorvastatin improves renal function but not renal blood flow indices in patients with peripheral arterial disease. Angiology 57:65-71 